\title{
Comportamento territorial, vocalização e biologia reprodutiva de Allobates olfersioides (Anura: Aromobatidae)
}

\author{
Sidieres M. da Costa ${ }^{1,2}$ (1) \& Eduardo J. dos R. Dias ${ }^{1,2}$ (1)
}

\author{
1 Laboratório de Biologia e Ecologia de Vertebrados, Departamento de Biociências, Campus Professor Alberto Carvalho, Universidade Federal de Sergipe (UFS), \\ Itabaiana, Brasil. \\ 2 Programa de Pós-Graduação em Biodiversidade e Evolução, Instituto de Biologia, Universidade Federal da Bahia (UFBA), Salvador, Brasil \\ (sidieres@hotmail.com, ejrdias@hotmail.com)
}

Recebido 8 setembro 2017

Aceito 3 julho 2019

Published 9 setembro 2019

DOI 10.1590/1678-4766e2019031

\begin{abstract}
Territorial behavior, vocalization and reproductive biology of Allobates olfersioides (Anura: Aromobatidae). For the amphibians the territoriality, the elaborate courtship and other forms of behaviors, seem to be more associated with species that exhibit the pattern of prolonged reproduction. Vocalization is an important biological aspect related to the reproduction and social behavior of the anurans. This is the first study with behavior and calls for the rocket frog, Allobates olfersioides (Lutz, 1925) and we record the territorial and courtship behavior in ethogram, describe and analyze its vocal repertoire and evaluate the climatic influence on the acoustic activity of the species. We observed 18 males of $A$. olfersioides by animal focal method, recording all individual activities for ten minutes to calculate the frequency of each action exhibited. Additionally, we played a previously recorded advertisement call to individual male frogs for analyze the territorial responses displayed by individual males during the work. For this anuran, we recorded 11 distinct behaviors and analyzed 14 advertisement calls that demonstrated that the call of $A$. olfersioides is a simple call composed of a single non-pulsed note, the call duration had a mean of $0.02 \mathrm{~s}$, the mean of intercall interval was of $0.35 \mathrm{~s}$ and the dominant frequency presented a mean of $5.67 \mathrm{kHz}$. The period of vocal activity was recorded during almost all months of the study (November 2015 to October 2016), except November and December, where the individuals presented acoustic inactivity. We believe that $A$. olfersioides presents a continuous reproduction (approximately 10 months), due to the absence of vocalizations during the driest months in November and December. Concerning the behavioral activities, $A$. olfersioides presents territorialist behavior patterns similar to other species of Aromobatidae, demonstrating the importance of the acoustic and visual signals exhibited by this anuran species of the Atlantic Forest.
\end{abstract}

KEYWORDS. Behavioral repertoire, ethogram, vocal activity, reproductive modes.

RESUMO.Em anfíbios a territorialidade, o cortejo elaborado e outras formas de comportamento, parecem estar mais associados a espécies que exibem o padrão de reprodução prolongado. A vocalização é um importante aspecto biológico relacionado à reprodução e ao comportamento social dos anuros. Este é o primeiro estudo com comportamento e vocalização da rã-foguete Allobates olfersioides (Lutz, 1925) e nós registramos em etograma o comportamento de territorialidade e corte, descrevemos e analisamos o seu repertório vocal e avaliamos a influência climática na atividade acústica da espécie. Ao todo 18 machos de $A$. olfersioides foram observados pelo método de animal focal, registrando todas as atividades individuais durante dez minutos. Adicionalmente, nós utilizamos o playback de um canto de advertência de macho adulto para analisar as respostas territoriais exibidas por indivíduos machos durante o trabalho. Para este anuro, registramos 11 comportamentos distintos e analisamos 14 cantos de anúncio que demonstraram que o canto de $A$. olfersioides é um canto simples e composto por uma única nota não pulsionada com duração média de $0,02 \mathrm{~s}$, intervalo médio entre cantos de $0,35 \mathrm{~s}$ e frequência dominante média de $5,67 \mathrm{kHz}$. O período de atividade vocal foi registrado durante quase todos os meses do estudo (novembro de 2015 a outubro de 2016), exceto novembro e dezembro, onde os indivíduos ficaram inativos quanto às atividades acústicas. Acreditamos que A. olfersioides apresente uma reprodução contínua (com duração de aproximadamente dez meses), devido à ausência de vocalizações durante os meses mais secos em novembro e dezembro. No que se refere às atividades comportamentais, A. olfersioides apresenta padrões de comportamento semelhantes a outras espécies de Aromobatidae, como também, o padrão territorialista já visto para o grupo, demonstrando a importância dos sinais acústicos e visuais.

PALAVRAS-CHAVE. Repertório comportamental, etograma, atividade vocal, modos reprodutivos.

Sapos aromobatídeos exibem comportamento territorial, corte complexa e oviposição terrestre (JunCÁ, 1998; Castillo-Trenn \& Coloma, 2008; Simões et al., 2013). Constituem um grupo monofilético de anuros que são conhecidos por suas cores aposemáticas, entretanto boa parte das espécies apresenta um padrão morfológico caracterizado por cores opacas e um padrão críptico, não sendo tóxicos (GRANT et al., 2006; VeRDADE \& RodRIGUES, 2007). O grupo recebeu bastante atenção nos últimos anos com diversos trabalhos sobre sua biologia e ecologia, com especial destaque aos aspectos comportamentais e reprodutivos, que evidenciaram a grande variedade comportamental exibida por esses organismos, como construção de ninhos para postura de ovos, comportamento de corte especializado, cuidado parental e disputas territoriais (HADDAD \& SAWAYA, 2000; Lima et al., 2002; SimõES et al., 2013). Ainda, pode ser encontrada uma grande dependência da sinalização visual nesses anuros em relação aos processos de corte e territorialismo, já que, esses 
animais utilizam esse artificio para reconhecer a receptividade sexual dos potenciais parceiros ou a defesa do território (HödL \& AMÉZQuita, 2001).

Visto que esses anuros apresentam essa variedade comportamental, uma ferramenta interessante na análise desses aspectos biológicos é o etograma, uma representação tabular da qualificação e quantificação dos comportamentos exibidos por uma espécie (Del-Claro, 2004). Porém, o etograma vem sendo pouco aplicado em estudos comportamentais de anuros, mesmo existindo trabalhos com vocalização (e.g. LimA et al., 2009; LuNA et al., 2010) indicando que há relação entre este aspecto da comunicação dos anuros com uma grande variedade de comportamentos sociais e reprodutivos (WelLs, 1977).

Entre as ferramentas complementares no estudo sobre comportamento e vocalização de anfíbios está o uso de playback, que vem sendo utilizado em estudos sobre atividades comportamentais (e.g. LIMA et al., 2002; GASSER et al., 2009; BASTOS et al., 2011). O playback mostra-se eficiente, já que, o canto de anúncio é um sinal específico emitido pelos machos e utilizado pelas fêmeas para distinguir os machos coespecíficos e, assim, formar casais reprodutores (RYAN \& RAND, 1993). As vocalizações podem ter, também, um importante papel nas interações sociais relacionadas à territorialidade (SUlLIVAN \& WAGNER, 1988). Ainda, as espécies pertencentes ao gênero Allobates são conhecidas por apresentarem uma grande variedade de comportamentos em resposta a cantos coespecificos (NARINS et al., 2003). Neste sentido, torna-se interessante analisar os comportamentos consequentes da emissão do playback, trazendo elementos da etologia que auxiliam na caracterização e organização dos comportamentos apresentados.

Estudos demonstram que fatores ambientais, como chuva, temperatura e umidade relativa influenciam as atividades reprodutivas de anuros (AICHINGER, 1987; MARSH, 2000; ZANK et al., 2010). Para animais que habitam regiões temperadas, há evidências de que a diversidade dos modos reprodutivos tem relação direta com a variação climática sazonal, onde a diferença de temperatura ao longo do ano é o principal fator responsável pelas respostas adaptativas de cada espécie (OSEen \& Wassersug, 2002; SAENZ et al., 2006). Nos trópicos o efeito do clima sobre a biologia reprodutiva dos anuros se dá por meio principalmente do regime de chuvas (VIEIRA et al., 2009; VASCONCElos et al., 2010), uma vez que a quantidade de água disponível nos microhabitats é o fator que mais interfere na atividade reprodutiva dos anuros ao longo do ano (ETERoviK \& SAZIMA, 2000).

Em anuros, a territorialidade, assim como outras formas de comportamento, como corte elaborada, parece estar associada às espécies que exibem o padrão de reprodução prolongada (Duellman \& TRUEB, 1994). Por exemplo, Allobates marchesianus (Melin, 1941) apresenta comportamento de defesa de território durante o período reprodutivo (JUNCÁ, 1998), existindo uma correlação positiva entre territorialismo e reprodução prolongada (WeLLS, 1977). Semelhante aspecto já foi registrado em Allobates granti que também apresenta características como corte complexa, territorialismo e reprodução contínua, com fêmeas apresentando ovócitos maduros ao longo do ano (KoK et al., 2006).

Allobates olfersioides, conhecido como rã-foguete, é um aromobatídeo que pode ser encontrado no chão das florestas primárias e secundárias de Mata Atlântica, e a presença de ovos maduros nas fêmeas durante todo o ano sugere que essa espécie apresenta reprodução contínua (VERDADE \& Rodrigues, 2007). Essa espécie apresenta reofílismo e seus girinos saem do ovo em ambiente terrestre úmido e são levados pelos pais para poças de pequenos riachos, aonde irão se alimentar até a metamorfose (LUTZ, 1954).

Apesar de A. olfersioides ser considerada uma espécie ameaçada de extinção na categoria vulnerável [VU - B1 ab (iii, iv) ] (HADDAD et al., 2016), poucos são os estudos realizados sobre a sua biologia, que se restringem a notas de distribuição geográfica, taxonomia e levantamentos de fauna (LuTZ, 1954; VERDADE \& Rodrigues, 2007; TinOCO et al., 2008).

A taxonomia e a sistemática das populações do gênero Allobates na Mata Atlântica são alvo de um interessante debate. Especialistas a partir de análises morfológicas (VERDADE \& Rodrigues, 2007) defendem a sinonimização de Allobates alagoanus (Bokermann, 1967), Allobates capixaba (Bokermann, 1967), e Allobates carioca (Bokermann, 1967) com Allobates olfersioides. Por outro lado, ForTi et al. (2017) sugerem, com base em análises do canto de advertência, que estas populações são formadas por pelo menos três espécies distintas. Em nosso trabalho não utilizamos elementos de canto para diferenciar indivíduos de populações diferentes. Sendo assim assumimos como identidade taxonômica Allobates olfersioides, este que ainda não possui sua vocalização descrita (GUERRA et al., 2018).

Nesta contribuição objetivamos registrar em etograma o comportamento de territorialidade e corte de Allobates olfersioides, descrever e analisar seu repertório vocal e avaliar a influência climática na atividade acústica da espécie para testar a hipotese de que a rã-foguete tem seu ciclo reprodutivo afetado pelo regime de chuvas em um fragmento de Mata Atlântica no Nordeste do Brasil.

\section{MATERIAL E MÉTODOS}

Área de estudo. O estudo foi desenvolvido no Parque Nacional Serra de Itabaiana (PNSI) localizado nos municípios de Areia Branca, Itabaiana, Laranjeiras, Itaporanga D'ajuda e Campo do Brito $\left(10^{\circ} 25^{\prime} 15^{\prime} \mathrm{S}, 37^{\circ} 25^{\prime} 15^{\prime}\right.$ 'O, datum WGS 84) (Fig.1). O PNSI apresenta formações não florestais que foram classificadas em quatro diferentes habitats naturais: areias brancas, vegetação arbustiva, áreas úmidas e áreas com gramíneas e ciperáceas (DANTAS \& Ribeiro, 2010), dando feições regionais que lembram fisionomicamente restingas, campos rupestres, brejos de altitude e cerrados (CARVALHO \& VILLAR, 2005). Está localizado na região agreste do Estado de Sergipe, nordeste do Brasil, uma zona de transição entre o Semiárido, ao oeste, e a Mata Atlântica, ao leste, com 


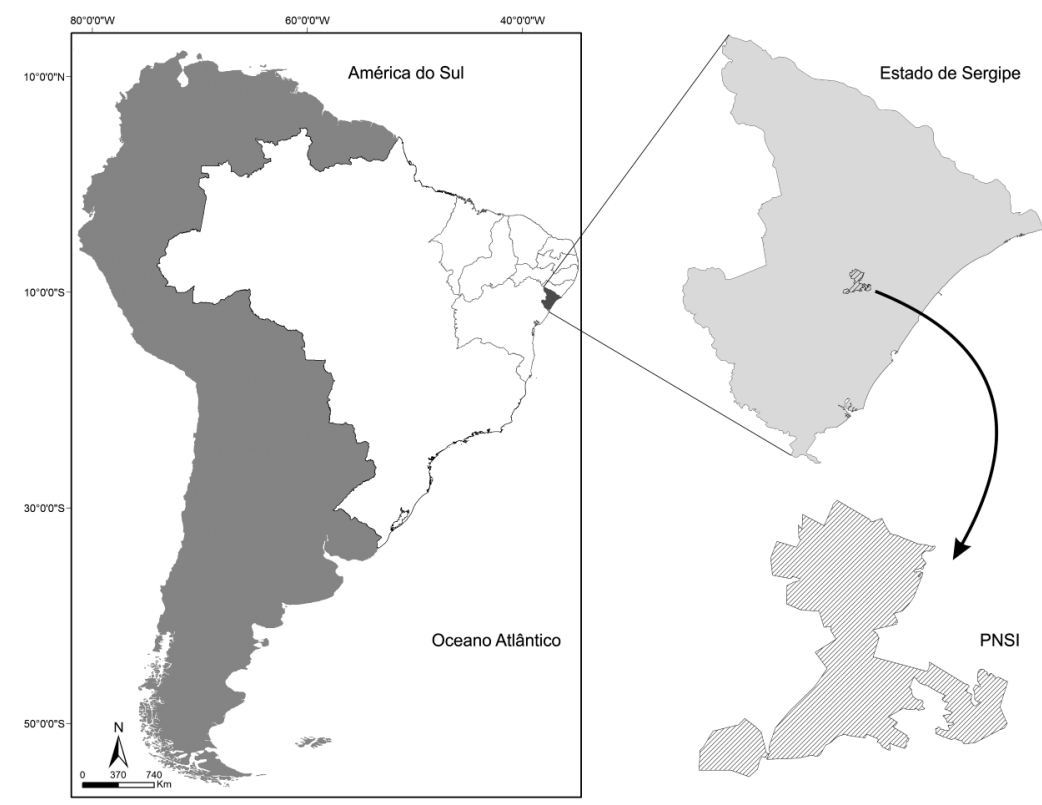

Fig. 1. Localização e limites (área hachurada) do Parque Nacional Serra de Itabaiana (PNSI), municípios de Areia Branca, Itabaiana, Laranjeiras,

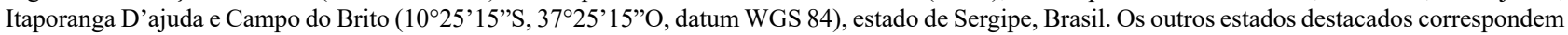
à Região Nordeste do Brasil.

fauna e flora de ambos os ecossistemas (VICENTE et al., 2005; Sobral et al., 2007).

Durante todas as expedições de coleta foram registrados os dados ambientais de temperatura e umidade relativa do ar, com o auxílio de uma estação multiparâmetro portátil. Os dados de precipitação foram obtidos no banco de dados climáticos para cidades mundiais (http://pt.climatedata.org/), os quais foram derivados das médias dos dados coletados entre 1982 e 2012, e definem duas estações para o município de Areia Branca: seca e chuvosa.

Repertório comportamental. Para análise dos comportamentos, os dados de campo foram registrados de novembro de 2015 a outubro de 2016 , em coletas mensais durante o período de atividade dos animais (06:00h às 15:00h) (VERDADE \& RoDRIGUES, 2007). As ações registradas para cada indivíduo foram categorizadas e contabilizadas para composição do etograma geral. Para diminuir efeitos do observador, não houve contato visual direto com o animal em análise, ao avistar o indivíduo focal, o observador se posicionava a uma distância que permitisse a visualização, a qual o animal pudesse realizar suas atividades. Nós utilizamos as seguintes abordagens para análise comportamentais: (i) método de todas as ações, que é utilizado como forma de análise prévia para registrar os possíveis comportamentos e o padrão de atividade dos animais em questão, visando construir um etograma prévio e o (ii) método de animal focal, que consiste em observar um único indivíduo do grupo por um período de amostragem pré-determinado e registrar todas as atividades realizadas por este animal em um etograma (AltMANN, 1974).
Adicionalmente às observações de comportamento livre, foi utilizado como estímulo, um trecho anteriormente gravado de um minuto do canto de anúncio de um indivíduo de $A$. olfersioides encontrado na área de estudo, obtido com o auxílio de um gravador digital e microfone externo direcional. Este arquivo não foi alterado de forma digital e continha apenas o canto de anúncio do indivíduo. Após a exibição deste playback, foram registrados os comportamentos exibidos por cada indivíduo para a elaboração do etograma. Os comportamentos não estimulados e os estimulados pelo playback para cada indivíduo foram observados nesta sequência: primeiro os comportamentos não estimulados e em seguida, os estimulados pelo playback durante dez minutos cada um e registrados para calcular frequência de cada ação exibida.

Para avaliar o comportamento territorialista e o tamanho do território foi utilizada a metodologia aplicada por Lima et al. (2002) para Allobates caeruleodactylus, que consiste em emitir com um gravador portátil o canto de anúncio da espécie e observar o deslocamento do macho em seu território; para isso, foi utilizado um arquivo de playback gravado anteriormente. $\mathrm{O}$ local onde um macho é avistado inicialmente é tomado como ponto central e à medida que $\mathrm{o}$ animal se aproxima do aparelho emissor, este é afastado em intervalos espaciais de $0,5 \mathrm{~m}$. O processo é repetido em no máximo seis direções até o momento em que o animal pare de seguir o gravador ou mude de direção. Para o cálculo da área foi aplicado o método do mínimo polígono convexo (White \& GARROTT, 1990) e para emissão do canto utilizado um gravador digital. As observações do território foram obtidas no período de fevereiro a abril de 2016. 
Repertório vocal. O canto dos machos foi gravado durante 1 a 1,5 minuto, a uma distância de aproximadamente $50-100 \mathrm{~cm}$, através de um gravador digital e microfone externo direcional. Os arquivos digitais foram amostrados em resolução de $44 \mathrm{kHz}$ e 16 bits, em extensão wave. Todos os cantos registrados foram analisados de forma individual. A análise dos cantos foi realizada com o programa Raven (Bioacoustics Research Program, 2014). Para todos os animais que tiveram seus cantos gravados, foram medidas temperatura e umidade do ar com o auxílio de uma estação multiparâmetro portátil. Com o intuito de descrever o repertório vocal de $A$. olfersioides, para cada canto foram analisados parâmetros de interesse segundo Duellman \& Trueb (1994), Martins \& Jim (2003) e Pombal \& Bastos (2003), sendo eles: duração do canto, intervalo entre cantos, frequência dominante e número de notas. Os exemplares que foram capturados após registro de canto encontram-se depositados na Coleção Herpetológica do Laboratório de Biologia e Ecologia de Vertebrados da Universidade Federal de Sergipe (UFS).

Biologia reprodutiva. Para avaliar a temporada reprodutiva, em conjunto com a análise de repertório vocal, foram analisadas associações entre as variáveis climáticas (temperatura, umidade do ar e precipitação) e o período de vocalização da espécie. Ainda registramos a distância dos machos vocalizando em relação ao riacho mais próximo utilizando trena com precisão de $1,0 \mathrm{~cm}$. Os pontos de encontro com os animais vocalizando foram marcados e identificados com fitas coloridas visando verificar o período reprodutivo de $A$. olfersioides. Foram acompanhados aspectos da biologia reprodutiva (cantos de anúncio e corte, processo de corte e territorialismo) durante um ano (novembro de 2015 a outubro de 2016) em visitas mensais (quatro dias/ mês) entre 06:00h às 15:00h, que é considerado o período de maior atividade da espécie (VERDADE \& RODRIGUES, 2007).

Para avaliar a relação entre a temperatura e a precipitação, bem como a relação entre a distância do riacho a temperatura e a precipitação ao longo do ano foi utilizada a correlação de Spearman. Adicionalmente foi utilizada análise de regressão para avaliar a relação entre atividade de vocalização (número de machos vocalizando) e o número de indivíduos ativos com as variáveis ambientais. As variáveis resposta em nossas análises foram a distância do riacho e o número de machos vocalizando, e as variáveis preditoras a temperatura e a umidade do ar. Em uma regressão múltipla a colinearidade entre os preditores pode interferir no resultado das variáveis resposta. Por esta razão, foi utilizado a priori o Coeficiente de Correlação Linear de Pearson (r) entre as variáveis ambientais. Diz-se que duas variáveis independentes exibem colinearidade completa se seu coeficiente de correlação é 1 , e completa falta de colinearidade se o coeficiente de correlação é 0 . Consideramos variáveis colineares aquelas com valores de $\mathrm{r}>0.4$ (e.g. TAYLOR et $a l ., 2005)$. Em condições de colinearidade selecionamos somente uma das variáveis preditoras (e. g. TAYLOR et al., 2005; LIPINSKI \& SANTOS, 2014). Para verificar a variação de temperatura ao longo dos meses, foi utilizado o teste de
Kruskal-Wallis, seguido do pós-teste de Student-NewmanKeuls. $\mathrm{O}$ valor de significância adotado foi $\mathrm{p}<0.05$, e para a realização das análises estatísticas foi utilizado o software BioEstat (Ayres et al., 2007).

\section{RESULTADOS}

Repertório comportamental. Após 360 minutos de observação em campo ( $\mathrm{n}=18$ indivíduos), foram registradas 207 ações comportamentais executadas pelos machos de Allobates olfersioides. Essas ações foram classificadas em 11 unidades comportamentais, separadas em duas categorias funcionais: (i) comportamentos não estimulados quando observados ad libitum e (ii) comportamentos estimulados exibidos durante a emissão do playback do canto (Tab. I).

Para a categoria dos comportamentos não estimulados foram registradas as unidades comportamentais canto de anúncio, corpo erguido, saco vocal inflado, canto de corte e deslocamento. Entre os comportamentos estimulados, as unidades foram canto de resposta, arqueamento, orientação, ziguezague, afastamento, retorno e ataque.

No que se refere ao comportamento de corte, foi possível observar apenas duas situações, ocorrido com dois casais. Em ambas, o macho apresentava atividade de vocalização em local amplamente visível (sob rocha com serapilheira ao redor e sob galho caído na serapilheira), ao perceber a aproximação da fêmea o macho mudou a orientação do corpo em direção a mesma. Após poucos minutos exibindo o canto de anúncio com a fêmea próxima, o macho emitiu o canto de corte e se aproximou da mesma. Neste momento a fêmea encaminhou-se para baixo da serapilheira, onde logo depois foi seguida pelo macho. Já embaixo das folhas, o macho voltou a emitir o canto de corte, alguns minutos depois, o macho saiu debaixo das folhas e retornou ao sítio de vocalização inicial. Após a saída do macho, a fêmea também saiu da serapilheira, ficou parada por alguns instantes e seguiu em direção oposta ao macho.

Durante as observações ainda foi observada uma interação entre machos, quando o macho residente de $A$. olfersioides estava vocalizando sob um tronco e um macho intruso se aproximou. Os machos ficaram a cerca de $10 \mathrm{~cm}$ um do outro e o intruso começou a vocalizar simultaneamente com o macho residente; este orientou-se em direção ao macho intruso, arqueou o tronco e continuou a vocalizar. Passados alguns segundos, o intruso cessou a vocalização e saiu do local. Não foi registrado nenhum tipo de interação física entre os machos.

O comportamento territorialista e de deslocamento referente a cinco indivíduos de $A$. olfersioides, observados no período de maio a junho, foi analisado quando os machos seguiam o playback até os possíveis limites de seu território, buscando definir o tamanho territorial individual ocupado. A média das áreas territoriais foi de $9.5 \mathrm{~m}^{2} \pm 5$. A maior área territorial registrada foi de $16.72 \mathrm{~m}^{2} \mathrm{e}$ a menor $4.26 \mathrm{~m}^{2}$ (Fig. 2). Foi apontado somente um macho repartindo território com outro rival e também apenas uma fêmea por território para cada macho observado em interação macho-fêmea $(n=2)$. 
Tab. I. Descrição dos comportamentos exibidos pelos machos da rã-foguete Allobates olfersioides $($ Lutz, 1925) $(\mathrm{n}=18)$ divididos em duas categorias: comportamentos não estimulados e comportamentos estimulados por playback, com o registro do número de ações comportamentais (AC), número de machos que emitiu cada um dos comportamentos (NM) e frequência.

\begin{tabular}{|c|c|c|c|c|c|}
\hline Categorias & $\begin{array}{l}\text { Unidades } \\
\text { comportamentais }\end{array}$ & Descrição & $\mathrm{AC}$ & NM & $\begin{array}{l}\text { Frequência } \\
(\%)\end{array}$ \\
\hline \multirow[t]{4}{*}{$\begin{array}{l}\text { Comportamentos } \\
\text { não estimulados }\end{array}$} & Canto de Anúncio & Emissão do canto de anúncio sem estímulo do playback & 18 & 18 & 100 \\
\hline & Saco Vocal Inflado & $\begin{array}{l}\text { Permanência do saco vocal inflado após a emissão do canto } \\
\text { de anúncio }\end{array}$ & 33 & 18 & 100 \\
\hline & Canto de Corte & Emissão do canto de corte & 2 & 2 & 11 \\
\hline & Deslocamento & Deslocamento do macho em direção à fêmea & 2 & 2 & 11 \\
\hline \multirow[t]{7}{*}{$\begin{array}{l}\text { Comportamentos } \\
\text { estimulados }\end{array}$} & Canto de Resposta & Emissão do canto de anúncio durante a reprodução do playback & 16 & 9 & 50 \\
\hline & Arqueamento & $\begin{array}{l}\text { Arqueamento do tronco após ouvir o playback, mas sem } \\
\text { emissão de canto }\end{array}$ & 33 & 18 & 100 \\
\hline & Orientação & $\begin{array}{l}\text { Mudança na orientação do corpo em direção ao playback, } \\
\text { porém sem aproximação }\end{array}$ & 19 & 14 & 77 \\
\hline & Ziguezague & Avanço em direção ao playback em movimentos diagonais & 19 & 14 & 77 \\
\hline & Afastamento & Afastamento em relação ao playback & 13 & 14 & 77 \\
\hline & Retorno & Retorno para o sítio inicial de vocalização & 12 & 13 & 72 \\
\hline & Ataque & $\begin{array}{l}\text { Aproximação em relação ao gravador, seguida de pulos em volta } \\
\text { ou sob o mesmo }\end{array}$ & 7 & 10 & 55 \\
\hline
\end{tabular}

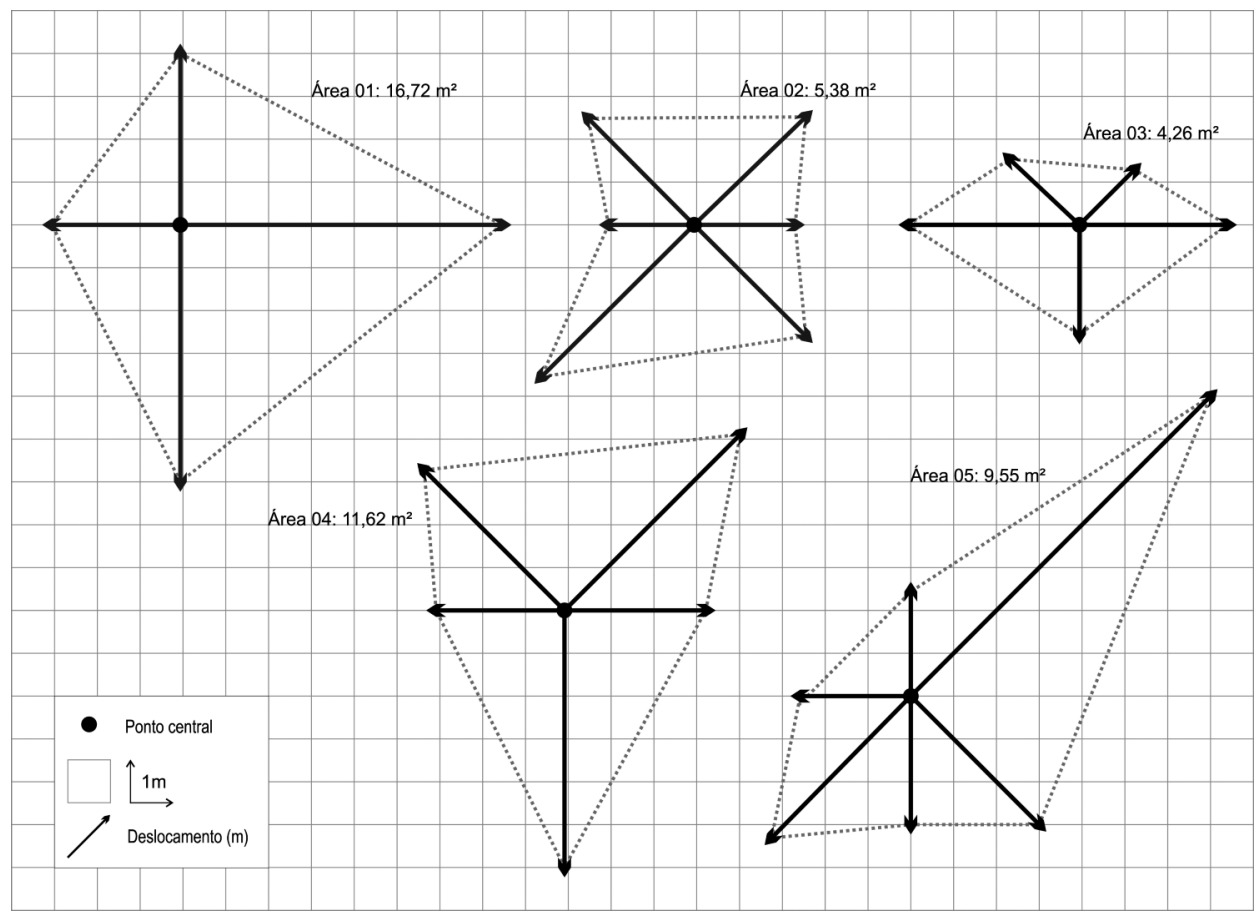

Fig. 2. Representação espacial das áreas territoriais para cinco machos da rã-foguete, Allobates olfersioides (Lutz, 1925), no período de fevereiro a abril

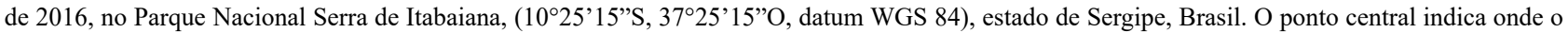
indivíduo monitorado foi avistado pela primeira vez.

Repertório vocal. Foram gravados os cantos de anúncio de 14 machos, totalizando aproximadamente 17,5 minutos de gravações. Ainda, em duas situações, foi possível registrar, após o canto de anúncio, o canto de corte da espécie, quando fêmeas se aproximaram de machos vocalizando em situações distintas. O período matutino (das $06: 00 \mathrm{~h}$ às 11:00 h) foi quando se registrou maior número de machos vocalizando e no vespertino (das 12:00 h às 15:00 h) foram observados de forma esporádica poucos machos vocalizando.

Foram registrados 1.455 cantos de anúncio produzidos por 14 machos; o canto de Allobates olfersioides pode ser caracterizado por ser simples, constituído por única nota não pulsionada, o que difere de outras espécies do grupo estudado (Tab. II). O canto apresentou duração média de 
Tab. II. Comparação entre os parâmetros de estrutura do canto de machos da rã-foguete Allobates olfersioides (Lutz, 1925) e outras 15 espécies do gênero descritos na literatura

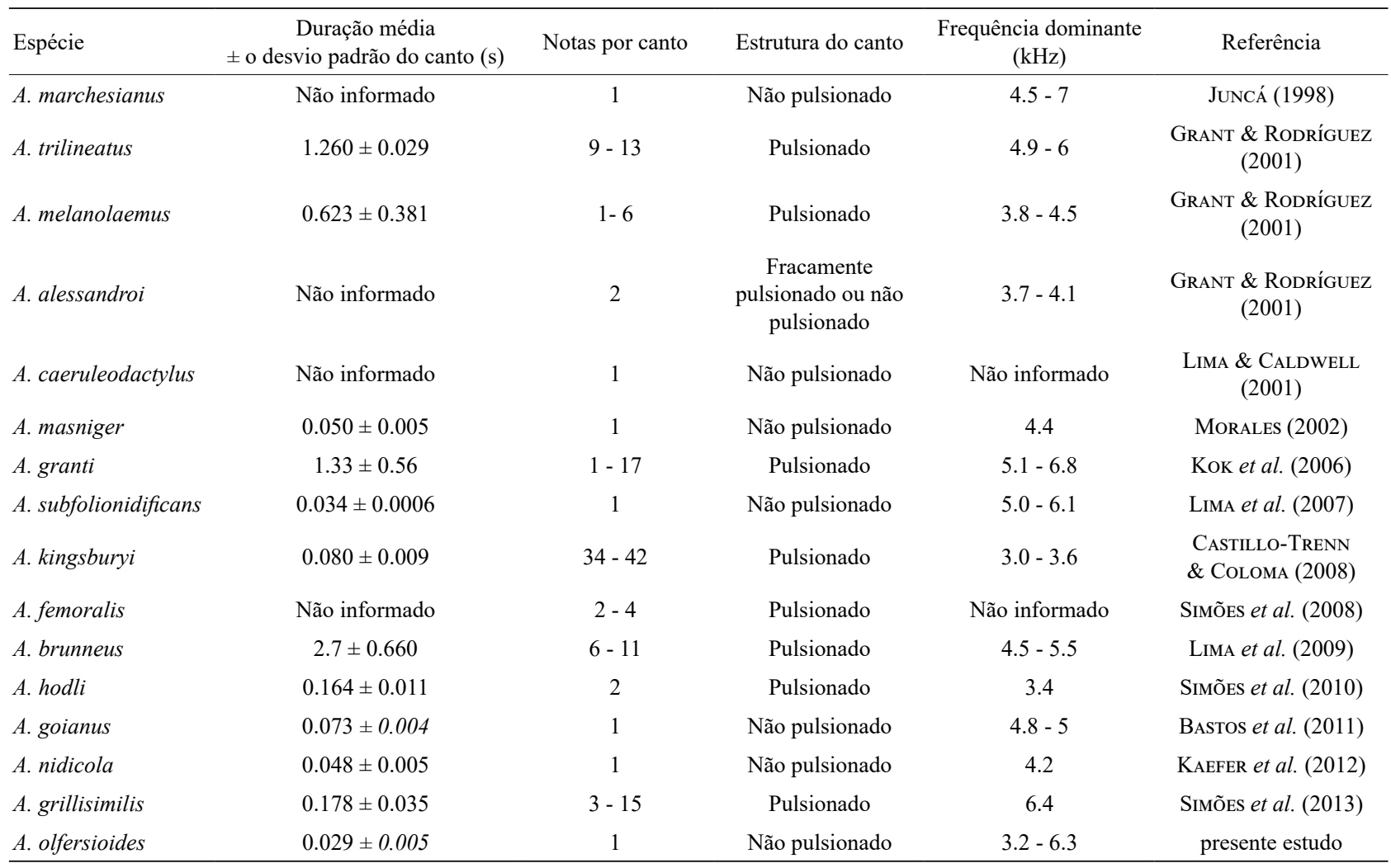

$0.02 \mathrm{~s} \pm 0.005$ (amplitude de 0,01-0,04 s), com intervalo médio entre cantos de $0,35 \mathrm{~s} \pm 0,23$ (amplitude de $0,10-3$ $\mathrm{s}$ ), enquanto a frequência dominante média foi de $5.67 \mathrm{kHz}$ \pm 0.33 (amplitude de $3.27-6.37 \mathrm{kHz}$ ) (Fig. 3).

Também foram observados e registrados dois cantos de corte emitidos por dois machos em situações diferentes, com a aproximação de indivíduos possivelmente fêmeas, os mesmos alteraram do canto de anúncio para o canto de corte e se aproximaram das possíveis fêmeas, seguindo para baixo da serapilheira após a emissão do canto de corte. Estes consistiram em cantos simples, de uma única nota pulsionada com duração média de $0,34 \mathrm{~s} \pm 0,11$ (amplitude de $0,19-0,52 \mathrm{~s}$ ), emitidos em intervalos médios de 3,85 $\mathrm{s} \pm 1,20$ (amplitude de 2,80-6,60 s), com uma média de 25,20 pulsos $\pm 2,34$ por nota (amplitude de $21-28$ pulsos) e frequência dominante média de $5.51 \mathrm{kHz} \pm 3.72$ (amplitude de $5.61-6.20 \mathrm{kHz}$ ) (Fig. 4).

Biologia reprodutiva. Indivíduos de $A$. olfersioides foram encontrados durante todas as expedições de coleta. No entanto, em novembro e dezembro de 2015 , sete indivíduos avistados encontravam-se escondidos sob pedras próximos ao rio e sem atividade acústica. De janeiro a outubro de 2016 foram registradas vocalizações em todos os dias de observação, sendo que houve um aumento no número de animais vocalizando durante a estação chuvosa (de março a agosto) em relação à estação seca (Fig. 5). No período estudado foram encontrados 29 indivíduos, cuja distância do rio foi em média de 7,09 $\mathrm{m} \pm 4,71$ (amplitude de 0 a
17,59 m) (Fig. 6). Os meses com menores distâncias foram novembro e dezembro, quando os animais se encontravam no riacho ou nas rochas as margens do mesmo, e a distância foi considerada como zero. Abril apresentou as maiores distâncias, com média de 12,55 $\mathrm{m} \pm 5$ (amplitude de 7,58 a 17,59 m) (Fig. 6).

A maior média de temperatura do ar foi de $30,61{ }^{\circ} \mathrm{C}$ $\pm 3,32$, registrada em novembro, enquanto julho apresentou a menor média, de $22,25^{\circ} \mathrm{C} \pm 0,53$. Quando analisada a temperatura entre os meses dentro de cada estação, foi possível perceber que os meses da estação seca (novembro a fevereiro, setembro e outubro) não diferiram significativamente entre $\mathrm{si}(\mathrm{H}=13.27, \mathrm{gl}=5, \mathrm{p}<0.05)$, o que também ocorreu para os meses da estação chuvosa (março a agosto $)(\mathrm{H}=15.23, \mathrm{gl}=5, \mathrm{p}<0.05)$. A temperatura do ar apresentou correlação significativa e estava negativamente relacionada à distância em que os animais se encontravam do riacho $(\mathrm{DR})(\mathrm{r}=-0.76, \mathrm{n}=12, \mathrm{p}<0.01)$. A umidade do ar e a DR não apresentou correlação significativa $(r=0.53$, $\mathrm{n}=12, \mathrm{p}=0.07)$. Houve correlação positiva e significativa entre a precipitação mensal e a DR $(\mathrm{r}=0.90, \mathrm{n}=12$, $\mathrm{p}<0.01$ ). Entre a temperatura do ar e a precipitação, houve correlação negativa e significativa $(\mathrm{r}=-0.74, \mathrm{n}=12$, $\mathrm{p}<0.01$ ).

Em média, o número de animais avistados mensalmente foi de 4,3 $\pm 0,9$ indivíduos, sendo a média de machos vocalizando de $2,7 \pm 1,7$ indivíduos. A temperatura e umidade relativa do ar apresentaram colinearidade $(-0.68)$ 


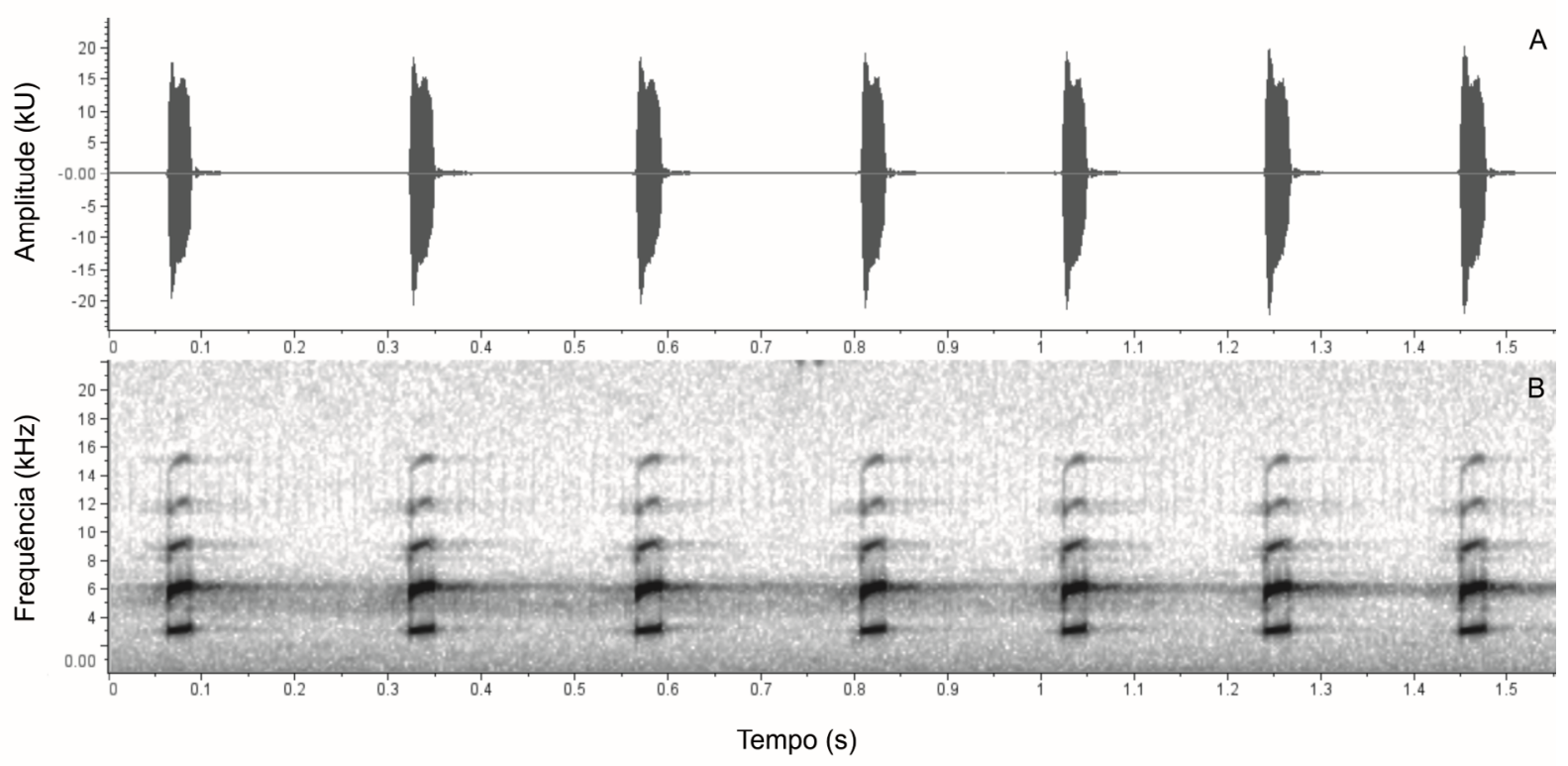

Fig. 3. Canto de anúncio da rã-foguete Allobates olfersioides (Lutz, 1925), (A) oscilograma e (B) espectrograma, temperatura de $25.5^{\circ} \mathrm{C}, 07: 50 \mathrm{~h}$, mês de maio de 2016, no Parque nacional Serra de Itabaiana (10²5’15”S, 37²5’15”O, datum WGS 84), Estado de Sergipe, Brasil.

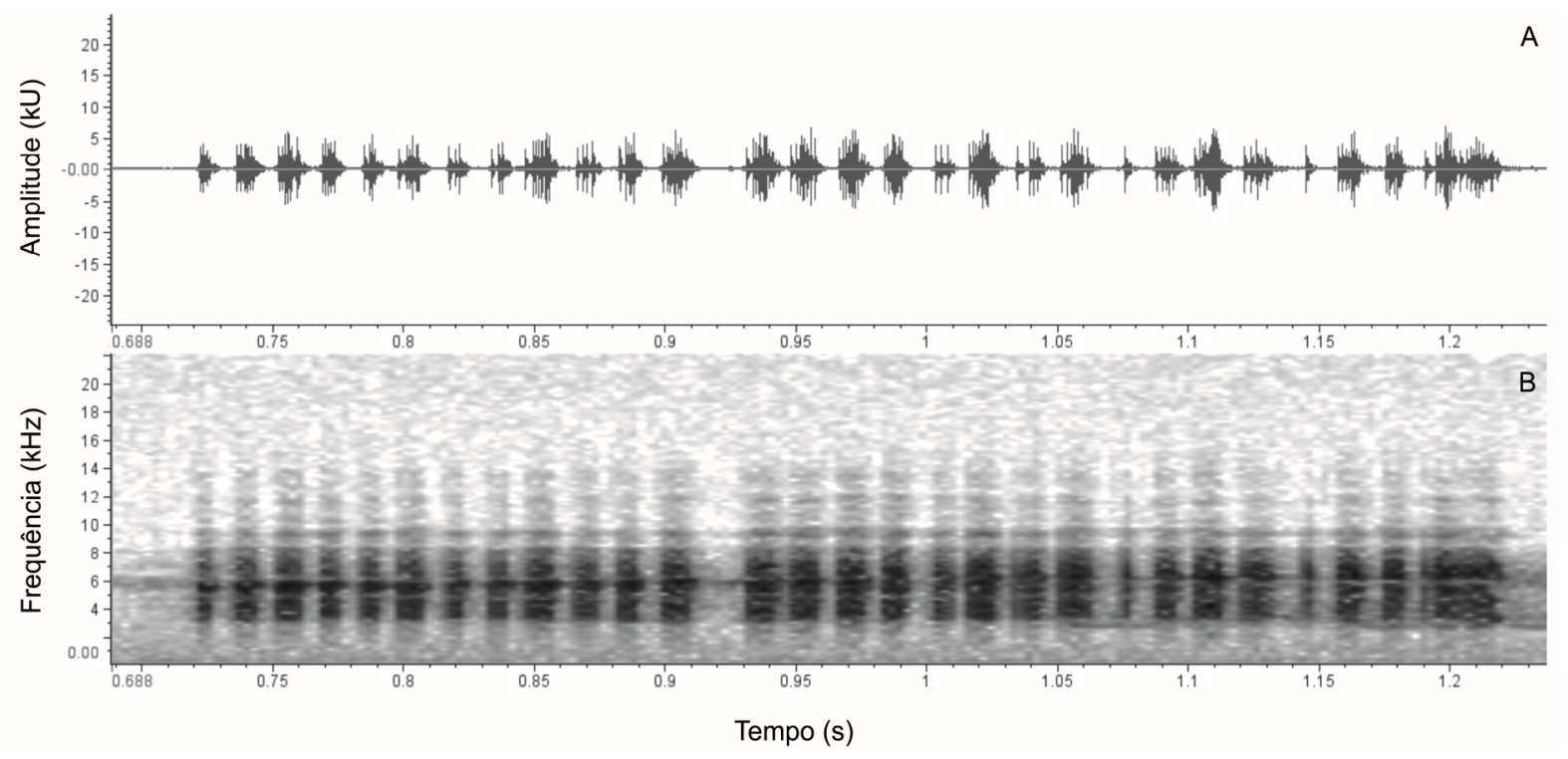

Fig. 4. Canto de corte de Allobates olfersioides (Lutz, 1925), (A) oscilograma e (B) espectrograma, temperatura de $26.6^{\circ} \mathrm{C}$ às $09: 34 \mathrm{~h}$, mês de junho de 2016, no Parque nacional Serra de Itabaiana ( $10^{\circ} 25^{\prime} 15^{\prime}$ 'S, $37^{\circ} 25^{\prime} 15^{\prime}$ 'O, datum WGS 84$)$, estado de Sergipe, Brasil.

por esta razão não foi possível realizar a análise de regressão múltipla com as variáveis independentes nem com o número de animais avistados, nem com aqueles vocalizando. Portanto, foi realizada análise de regressão linear simples entre as variáveis dependentes (número de animais avistados e de machos vocalizando) com a umidade relativa do ar. Assim, a quantidade de animais avistados não esteve relacionada com a umidade relativa do ar $\left(\mathrm{R}^{2}=0.01 ; \mathrm{n}=51 ; \mathrm{p}=0.87\right)$. No entanto, a atividade de vocalização esteve positiva e significativamente relacionada com esta variável ambiental que explicou cerca de $40 \%$ da atividade dos machos $\left(\mathrm{R}^{2}=\right.$ $0.42 ; \mathrm{n}=33 ; \mathrm{p}=0.02$ ) (Fig. 7). 


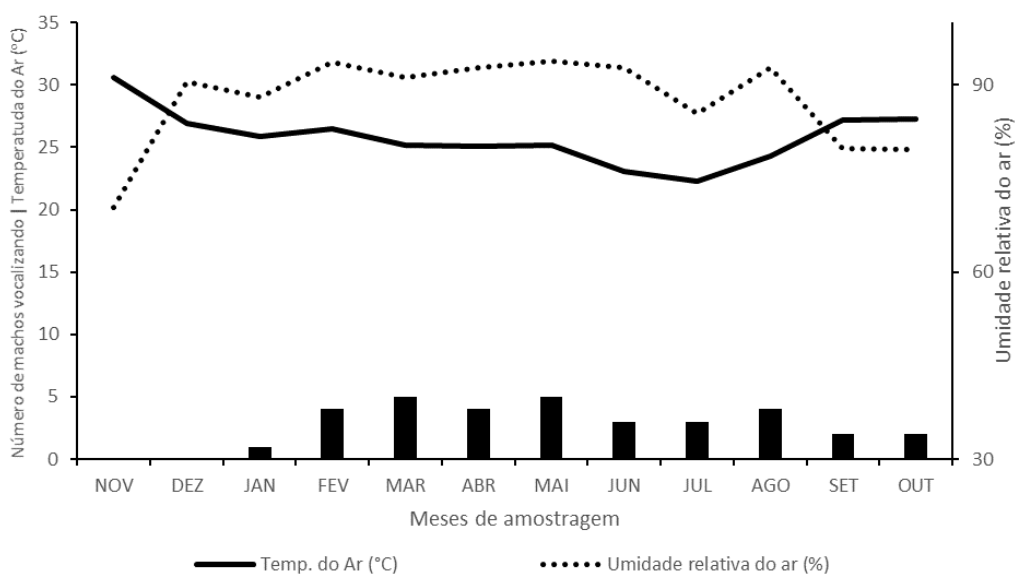

Fig. 5. Número de machos da rã-foguete, Allobates olfersioides (Lutz, 1925), vocalizando e variação da temperatura do ar e umidade relativa do ar nos 12 meses de amostragem no Parque Nacional Serra de Itabaiana (10²5'15”S, 37²5’15”O, datum WGS 84), Estado de Sergipe, Brasil. As barras representam o número de machos vocalizando.

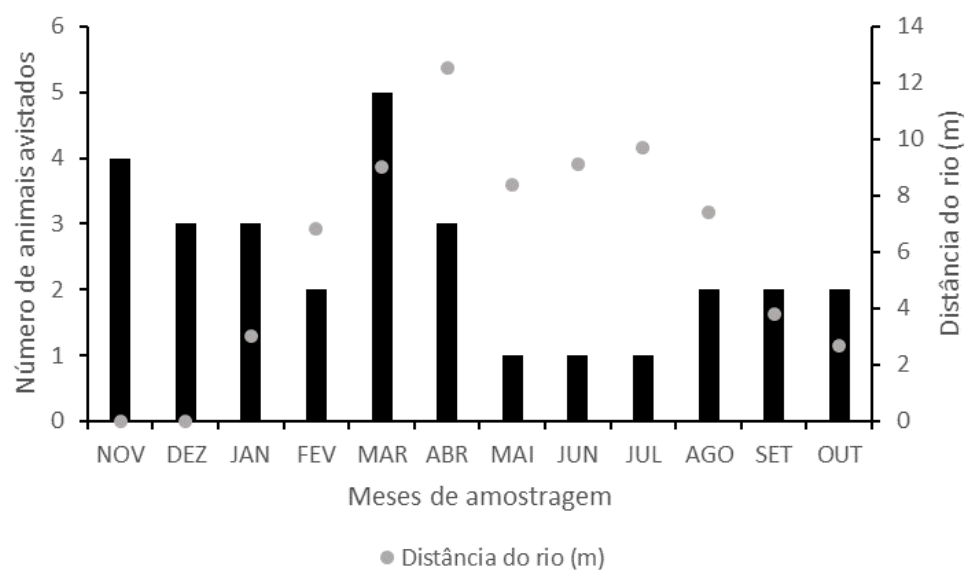

Fig. 6. Número de indivíduos da rã-foguete, Allobates olfersioides (Lutz, 1925), avistados de novembro de 2015 a outubro de 2016 e a distância média que se encontravam do rio no Parque Nacional Serra de Itabaiana ( $\left(10^{\circ} 25^{\prime} 15^{\prime}\right.$ 'S, $37^{\circ} 25^{\prime} 15^{\prime}$ 'O, datum WGS 84$)$, estado de Sergipe, Brasil.

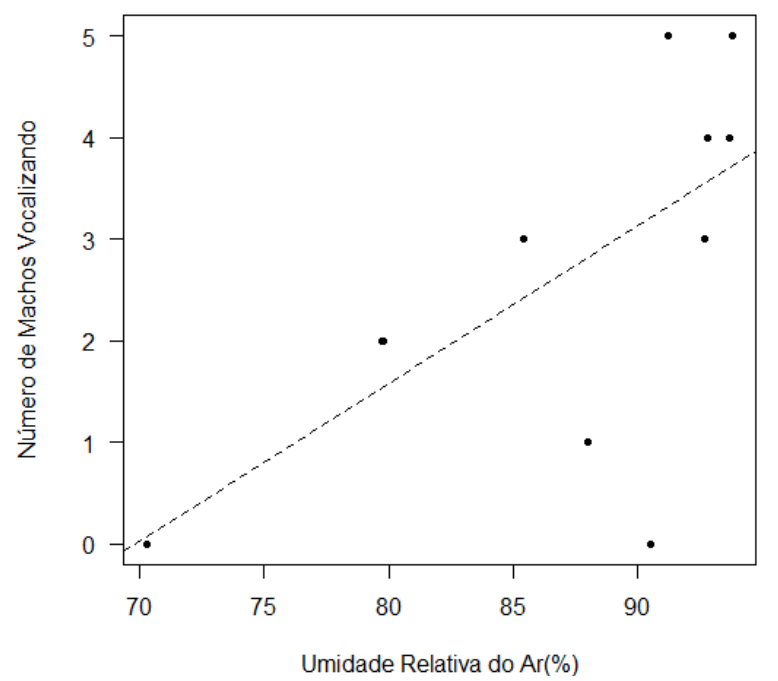

Fig. 7. Relação entre o número de machos da rã-foguete, Allobates olfersioides (Lutz, 1925), vocalizando e da umidade relativa do ar $\left(\mathrm{R}^{2}=\right.$ $0.42 ; \mathrm{n}=33 ; \mathrm{p}=0.02)$ no Parque Nacional Serra de Itabaiana $\left(10^{\circ} 25^{\prime} 15^{\prime \prime} \mathrm{S}\right.$, $37^{\circ} 25^{\prime} 15^{\prime}$ 'O, datum WGS 84), estado de Sergipe, Brasil. A linha tracejada representa a equação ajustada do modelo.

\section{DISCUSSÃO}

Com base nos resultados obtidos, foi evidenciada a variedade comportamental que Allobates olfersioides apresentou de forma não estimulada e quando estimulado. Os comportamentos não estimulados, considerados aqui como comportamentos naturais da espécie no processo reprodutivo, porém sem o estímulo do gravador (canto de anúncio, saco vocal inflado, canto de corte e deslocamento) e os comportamentos estimulados (canto de resposta, arqueamento, orientação, ziguezague e retorno) não fugiram do padrão relatado em outras contribuições com Aromobatidae como, por exemplo, em Rheobates palmatus (Werner, 1899) (LUDDECKE, 1999), Allobates femoralis (Boulenger, 1884) (NARINs et al., 2003) e Allobates granti (КоK et al., 2006).

Como esperado, o canto de resposta foi emitido logo após o estímulo do playback. Diversos estudos relacionados a Aromobatidae demonstraram comportamentos territoriais e agressivos (GoOdman, 1971; RoITHMaIR, 1994; JUNCÁ, 
1998; Summers, 2000), como o imediato canto de resposta e o ataque ao gravador, o que pode ser visto no presente trabalho, com as respostas tanto na vocalização como também nos comportamentos apresentados com relação ao playback.

Mudança de orientação, movimentos em ziguezague, ataque e afastamento em relação ao playback também foram comportamentos registrados com frequência, como retratado em Lima et al. (2002) para Allobates caeruleodactylus (LimA \& CAldwell, 2001). O comportamento de arqueamento, que foi observado durante todas as respostas visuais ao playback, é característico para espécies de Allobates como A. marchesianus e A. kingsburyi (Boulenger, 1918) (JunCÁ, 1998; Castillo-Trenn \& Coloma, 2008). O comportamento de erguer o corpo é usado para a demarcação de território podendo evitar combates e evitar prejuízos físicos e energéticos aos indivíduos envolvidos (Pough et al., 2008). Assim como ataques ao gravador realizados pelos machos, também foram registrados e já relatados em outras espécies (e.g., A. femoralis, LunA et al., 2010). Nas interações entre machos e fêmeas, os comportamentos observados também foram de acordo com o gênero, segundo a literatura (SIMÕES et al., 2013; Lima et al., 2007).

Para a área ocupada, foi verificado que dentro de uma área média de $9,5 \mathrm{~m}^{2}$ por indivíduo, nenhum outro macho foi avistado, e, quando avistado, foi expulso pelo macho residente, o que implica que não existe repartição de espaço entre machos dentro de um mesmo território, afirmando a territorialidade e a eficiência dos sinais acústicos e visuais citados anteriormente.

Para o gênero Allobates foram descritas anteriormente vocalização de 15 espécies: A. marchesianus, A. trilineatus (Boulenger, 1884), A. melanolaemus (GRANT \& RodríGUEZ, 2001), A. alessandroi (Grant \& Rodriguez, 2001), $A$. caeruleodactylus; A. masniger (Morales, 2002), A. granti, A. subfolionidificans (Lima, Sanchez \& Souza, 2007), $A$. kingsburyi, A. femoralis, A. brunneus (Lynch, 1975), A. hodli (Simões, Lima \& Farias, 2010), A. goianus (Bokermann, 1975), A. nidicola (Caldwell \& Lima, 2003) e A. grillisimilis (Simões, Sturaro, Peloso \& Lima, 2013).

O canto de anúncio de Allobates olfersioides é simples, constituído por uma única nota simples não pulsionada, semelhante aos cantos já descritos para seis espécies do gênero: A. marchesianus (JUNCÁ, 1998); A. caeruleodactylus (Lima \& CALdwell, 2001); A. masniger (Morales, 2002), A. subfolionidificans (Lima et al., 2007); A. goianus (BAStos et al., 2011); e A. nidicola (KAEFER et al., 2012). Esse canto difere de outras nove: A. trilineatus, $A$. melanolaemus, $A$. alessandroi (GRANT \& RodríGUEZ, 2001), A. granti (KoK et al., 2006), A. kingsburyi (CASTILLO-TrenN \& Coloma, 2008), A. femoralis (Simões et al., 2008), A. brunneus (Lima et al., 2009), A. hodli (SimÕES et al., 2010) e A. grillisimilis (SimÕES et al., 2013), por estas apresentarem cantos compostos por mais de uma nota, em sua grande maioria, pulsionadas.

Não foram observados machos em atividade de vocalização em todo o período amostrado, com indivíduos inativos nos meses de novembro e dezembro de 2015. A ausência de machos vocalizando em alguns meses pode ser explicada pelas temperaturas mais elevadas, umidade relativamente baixa e pelo período apresentar as menores precipitações registradas durante as coletas para os referidos meses. Sabe-se que a temperatura desempenha um papel importante na atividade de vocalização e comportamental destes animais (SANTOS et al., 2008; CANAVERo et al., 2009). Anuros que vivem em áreas tropicais podem estar ativos durante todo o ano e ter padrão de reprodução contínuo, porém, a precipitação é considerada o principal fator extrínseco associado à sua reprodução (CURI et al., 2014).

As médias de temperatura e umidade relativa do ar foram inversamente proporcionais entre si durante os meses de coleta; neste sentido, estar próximo ao riacho quando a temperatura estava elevada e a umidade baixa pode ser vantajoso para os indivíduos de A. olfersioides. Quando a umidade estava alta, os anfíbios podiam se manter mais distantes do riacho, já que, com índices de chuva maiores, a serapilheira fica mais úmida e cria microhabitats favoráveis, inclusive para o acasalamento, diminuindo a dependência do riacho.

Espécies filogeneticamente próximas, como $A$. subfolionidificans (Lima, SANchez \& Souza, 2007), A. kingsburyi e A. brunneus (Lynch, 1975) utilizam a serapilheira como sítio de reprodução e postura dos ovos (Lima et al., 2007; CAstillo-Trenn \& Coloma, 2008; Lima et al., 2009). Além disso, já se tem registros de que os girinos de Allobates olfersioides são levados por um dos progenitores para pequenos riachos, onde se alimentam até a metamorfose (VERDADE \& RODRIGUES, 2007); isso pode indicar que tanto o acasalamento como a oviposição desta espécie pode ocorrer na serapilheira das bordas próximas ao riacho, quando a precipitação está elevada, seguido pelo transporte dos girinos para o riacho.

No presente estudo, verificamos que $A$. olfersioides não apresentou atividade vocal em todo o período de estudo, demonstrando alguns períodos de inatividade acústica, como observado nos resultados. A partir de janeiro até outubro (fim das nossas observações em campo) houve ocorrência de canto, resultado semelhante ao obtido por VERDADE \& RODRIGUES (2007).

Sabe-se que as atividades reprodutivas em anuros são intensamente influenciadas pelos fatores abióticos (BLAIR, 1960; TAYLOR et al., 2005; VOLKMER et al., 2017). Variáveis como temperatura, precipitação e umidade atmosférica são essenciais para suas atividades reprodutivas e, em zonas temperadas, tanto a precipitação quanto a temperatura são fatores abióticos que influenciam os padrões temporais de reprodução em anuros (WISNIEWSKI et al., 1980; CALDWELL, 1987; Semlitsch \& Gibbons, 1988;). A atividade de vocalização de Allobates olfersioides tem relação com a umidade relativa do ar, visto que ela explicou quase a metade do número de machos vocalizando. Entretanto esta variável ambiental não explica sozinha toda essa variação. Outras variáveis ambientais e até mesmo interações interespecíficas podem ser importantes para a atividade de vocalização de machos da rã-foguete. Pluviosidade, fotoperíodo e temperatura da água são variáveis que podem apresentar 
relações mais fortes no que se refere a atividade vocal em anuros. VOLKMER et al. (2017) demonstrou que dentre as variáveis climáticas analisadas, a temperatura da água é a mais importante para explicar a variação da abundância de machos da perereca Sphaenorhynchus surdus, em atividade de vocalização. Essa relação também foi verificada por OSEEN \& WASSERSUG (2002) para cinco espécies de anuros na América do Norte. Porém esses aspectos, até o momento, não foram estudados para $A$. olfersioides.

Acreditamos que $A$. olfersioides apresente uma reprodução contínua (que se estende por aproximadamente dez meses) como proposto por Wells (1977), devido à ausência de vocalizações durante os meses mais secos em novembro e dezembro. Duellman \& TRUEB (1994) propõem que em anuros a territorialidade, assim como outras formas de comportamento como corte elaborada, parece estar associada às espécies que exibem o padrão de reprodução prolongada.

Com a ausência de atividade vocal nos meses de novembro e dezembro, e pela diminuição da mesma nos meses da estação seca, é perceptível que existe um pico de atividade de vocalização nos meses da estação chuvosa. Tal resultado pode ser explicado pela maior disponibilidade de ambientes propícios para a reprodução e pela diminuição da temperatura, caracterizando o padrão de reprodução de Allobates olfersioides como contínua com variação sazonal.

Estudos que tratem sobre a vocalização de anuros, relacionada com os comportamentos exibidos durante os processos de estabelecimento de território e de corte, contribuem para o conhecimento da história natural e das relações sociais da espécie. Ainda, a relação entre padrões de vocalização e variáveis ambientais trazem uma maior gama de informações sobre a reprodução de $A$. olfersioides; contudo, as próximas abordagens devem integrar análises morfológicas e histológicas das gônadas para avaliar os estágios reprodutivos de machos e fêmeas na população, a fim de obter resultados ainda mais concisos.

Agradecimentos. Aos integrantes do Laboratório de Biologia e Ecologia de Vertebrados (LABEV), de forma especial a Tainara Silva, Jefferson Oliveira e Roberto Mattos pelo auxílio em campo e em laboratório. À Prof ${ }^{a}$ Dra. Flora Acuña Juncá e a Danielle Lima Alves por disponibilizarem o registro vocal de $A$. olfersioides. Agradecemos também a Fundação de Amparo à Pesquisa do Estado da Bahia (FAPESB) pela concessão da bolsa (Processo $n^{\circ}$ BOL3022/2015) e o Instituto Chico Mendes de Conservação da Biodiversidade (ICMBio) pelas licenças de $\mathrm{n}^{\circ}$ 51442-1 e $\mathrm{n}^{\circ}$ 20788-1.

\section{REFERÊNCIAS}

AICHINGER, M. 1987. Annual activity patterns of anurans in a seasonal neotropical environment. Oecologia 71:583-592.

Altmann, J. 1974. Observational Study of Behavior: Sampling Methods. Behaviour 49(3/4):227-267.

Ayres, M.; Ayres Júnior, M.; Ayres, D. L. \& Santos, A. A. 2007. BIOESTAT - Aplicações estatísticas nas áreas das ciências biomédicas. Belém, Mamirauá. 364p.

Bastos, R. P.; Signorelli, L.; Morais, A. R.; Costa, T. B.; Lima, L. P. \& Pombal JR, J. P. 2011. Advertisement Calls of Three Anuran Species (Amphibia) from the Cerrado, Central Brazil. South American Journal of Herpetology 6(2):67-72.

Bioacoustics Research Program. 2014. Raven Pro: Interactive Sound Analysis Software (Version 1.5) [Computer software]. Ithaca, The
Cornell Lab of Ornithology. Disponível em $<$ http://www.birds.cornell. edu/raven $>$.

BlaIR, W. F. 1960. A breeding population of the Mexican toad (Bufo valliceps) in relation to its environment. Ecology 41:165-174.

CALDwell, J. P. 1987. The demography and life history of two species of chorus frogs (Anura: Hylidae) in South Carolina. Copeia 1987:114-127.

Canavero, A.; Arim, M. \& Brazeiro, A. 2009. Geographic variations of seasonality and coexistence in communities: The role of diversity and climate. Austral Ecology 34:741-750.

Carvalho, C. M. \& VilaR, J. C. 2005. Introdução-Levantamento da Biota do Parque Nacional Serra de Itabaiana. In: CARVAlHo, C. M. \& VILAR, J. C. eds. Parque Nacional Serra de Itabaiana - Levantamento da Biota. Aracaju, Ibama, Biologia Geral e Experimental - Universidade Federal de Sergipe, p. 9-14.

Castillo-Trenn, P. \& Coloma, L. A. 2008. Notes on behaviour and reproduction in captive Allobates kingsburyi (Anura: Dendrobatidae), with comments on evolution of reproductive amplexus. International Zoo Yearbook 42:58-70.

Curi, L. M.; Olea, G. B.; Álvarez, B. B.; Céspedez, J. A. \& Lombardo, D. M. 2014. Reproductive aspects of Dendropsophus sanborni (Anura, Hylidae) in northeastern Argentina. Iheringia, Série Zoologia 104(4):432-438.

Dantas, T. V. P. \& Ribeiro, A. S. 2010. Caracterização da vegetação do Parque Nacional Serra de Itabaiana, Sergipe-Brasil. Biotemas 23(4):9-18.

Del-Claro, K. 2004. Comportamento Animal: Uma introdução à ecologia comportamental. Jundiaí, Conceito. 132p.

Duellman, W. E. \& Trueb, L. 1994. Biology of Amphibians. Baltimore, The Johns Hopkins University Press. 670 p.

Eterovick, P. C. \& SAZima, I. 2000. Structure of an anuran community in a montane meadow in southeastern Brazil: effects of seasonality, habitat, and predation. Amphibia-Reptilia 21:439-461.

ForTI, L. R.; DA SILVA, T. R. A. \& TOLEDO, L. F. 2017. The acoustic repertoire of the Atlantic Forest Rocket Frog and its consequences for taxonomy and conservation (Allobates, Aromobatidae). ZooKeys 692:141-153. Disponível em <https://doi.org/10.3897/zookeys.692.12187>

GASSER, H.; AMÉZQuitA, A. \& HodL, W. 2009. Who is calling? Intraspecific Call Variation in the Aromobatid Frog Allobates femoralis. Ethology 115:596-607.

Goodman, D. E. 1971. Territorial behavior in a Neotropical frog, Dendrobates granuliferus. Copeia, 1971:365-379.

Guerra, V.; Lluisa, D.; Gambale, P. G.; De Morais, A. R.; Márquez, R. \& Bastos, R. P. 2018. The advertisement calls of Brazilian anurans: Historical review, current knowledge and future directions. Plos One 13(1):1-22

Grant, T.; Frost, D. R.; Caldwell, J. P; Gagliardo, R.; Haddad, C. F. B.; KoK, P. J. R.; Means, D. B.; Noonan, B. P.; Schargel, W. E. \& Wheeler, W. C. 2006. Phylogenetic systematics of Dart-Poison Frogs and their relatives (Amphibia: Athesphatanura: Dendrobatidae). Bulletin of the American Museum of Natural History 299:1-262.

Grant, T. \& Rodríguez, L. O. 2001. Two New Species of Frogs of the Genus Colostethus (Dendrobatidae) from Peru and a Redescription of C. trilineatus (Boulenger, 1883). American Museum Novitates 3355:1-24.

HADDAD, C. F. B. \& SAWAYA, R. J. 2000. Reproductive modes of Atlantic Forest hylid frogs: a general overview and the description of a new mode. Biotropica 32(4b):862-871.

Haddad, C. F. B.; Segalla, M. V.; Bataus, Y. S. L.; Uhlig, V. M.; Batista, F. R. Q.; Garda, A.; Hudson, A. A.; Cruz, C. A. G.; Strüsmann, C.; Brasileiro, C. A.; Silvano, D. L.; Nomura, F.; Pinto, H. B. A.; Amaral, I. B.; Gasparini, J. L. R.; Lima, L. P.; Martins, M. R. C.; Hoogmoed, M. S.; Colombo, P.; Valdujo, P. H.; Garcia, P. C. A.; Feio, R. N.; Brandão, R. A.; Bastos, R. P. \& Caramaschi, U. 2016. Avaliação do Risco de Extinção de Allobates olfersioides (A. Lutz, 1925). Processo de avaliação do risco de extinção da fauna brasileira. ICMBio. Disponível em: $<$ http://www.icmbio.gov.br/portal/ biodiversidade/fauna-brasileira/estado-de-conservacao/7498-anfibiosallobates-olfersioides.html $>$. Acessado 06 de janeiro de 2019.

HöDL, W. \& AmÉzQuita, A. 2001. Anuran communication. Washington D. C., Smithsonian Institution Press. Chapter 10, Visual signaling in anuran amphibians; p. 121-141. 
JunCÁ, F. A. 1998. Reproductive Biology of Colostethus stepheni and Colostethus marchesianus (Dendrobatidae), with the Description of a New Anuran Mating Behavior. Herpetologica 54(3):377-387.

Kaefer, I. L.; Tsuji-Nishikido, B. M. \& Lima, A. P. 2012. Beyond the river: underlying determinants of population acoustic signal variability in Amazonian direct-developing Allobates (Anura: Dendrobatoidea). Acta Ethologica 15:187-194.

KoK, P. J. R.; Macculloch, R. D.; Gaucher, P.; Poelman, E. H.; Bourne, G. R.; LATHROP, A. \& LENGLET, G. L. 2006. A new species of Colostethus (Anura, Dendrobatidae) from French Guiana with a redescription of Colostethus beebei (Noble, 1923) from its type locality. Phyllomedusa 5(1):43-66.

Lima, A. P. \& CALdwell, J. P. 2001. A new Amazonian species of Colostethus with sky blue digits. Herpetologica 57(2):180-189.

Lima, A. P.; Caldwell, J. P. \& Biavati, G. M. 2002. Territorial and Reproductive Behavior of an Amazonian Dendrobatid Frog, Colostethus caeruleodactylus. Copeia 2002(1):44-51.

Lima, A. P.; Caldwell, J. P. \& Strussmann, C. 2009. Redescription of Allobates brunneus (Cope) 1887 (Anura: Aromobatidae: Allobatinae), with a description of the tadpole, call, and reproductive behavior. Zootaxa 1988:1-16.

LimA, A. P.; SANChez, D. E. A. \& SouZA, J. R. D. 2007. A New Amazonian Species of the Frog Genus Colostethus (Dendrobatidae) that Lays its Eggs on Undersides of Leaves. Copeia 2007(1):114-122.

LIPINSKI, V. M. \& SANTOS, T. G. 2014. Estrutura e organização espacial de duas comunidades de anuros do bioma Pampa. Iheringia, Série Zoologia 104(4):462-468.

LUDDECKE, H. 1999. Behavioral aspects of the reproductive biology of the Andean frog Colostethus palmatus (Amphibia: Dendrobatidae). Revista Acadêmica Colombiana de Ciências 23:303-316.

LunA, A. G.; HodL, W. \& AMÉZquiTA, A. 2010. Colour, size and movement as visual subcomponents in multimodal communication by the frog Allobates femoralis. Animal Behaviour 79:739-745.

Lutz, B. 1954. Anfíbios Anuros do Distrito Federal. Memórias do Instituto Oswaldo Cruz 1:219-238.

Morales, V. C. 2002. Sistemática y biogeografía del grupo trilineatus (Amphibia, Anura, Dendrobatidae, Colostethus), con descripción de once especies nuevas. Publicaciones de La Asociación de Amigos de Doñana 13:1-59.

MARSH, D. M. 2000. Variable responses to rainfall by breeding tungara frogs. Copeia 2000:1104-1108

MarTinS, I. A. \& JIM, J. 2003. Bioacoustics analysis of advertisement call in Hyla nana and Hyla sanborni (Anura, Hylidae) in Botucatu, São Paulo, Brazil. Brazilian Journal of Biology 63(3):507-516.

Narins, P. M.; HoLD, W. \& GrabUL, D. S. 2003. Biomodal signal requisite for agonistic behavior in a dart-poison frog, Epipedobates femoralis. Proceedings of the National Academy of Sciences 100(2):577-580.

OSEEN, K. L. \& WASSERSUG, R. J. 2002. Environmental factors influencing calling in sympatric anurans. Oecologia 133:616-625.

Pombal JR., J. P. \& Bastos, R. P. 2003. Vocalizações de Scinax perpusillus (A. Lutz \& B. Lutz) e S. arduous Peixoto (Anura, Hylidae), com comentários taxonômicos. Revista Brasileira de Zoologia 20(4):607610.

Pough, F. H.; Janis, C. M.; Heiser, J. B. 2008. Vertebrate Life. 4ed. New Jersey, Upper Saddle River. 750p.

RoithmaIR, M. E. 1994. Male Territoriality and Female Mate Selection in the Dart-Poison Frog Epipedobates trivittatus (Dendrobatidae, Anura). Copeia 1994(1):107-115.

Ryan, M. J. \& RAND, A. S. 1993. Species recognition and sexual selection as a unitary problem in animal communication. Evolution 47(2):647-657.

Saenz, D.; Fitzgerald, L. A.; Baum, K. A. \& Conner, R. N. 2006. Abiotic Correlates of Anuran Calling Phenology: The Importance of Rain, Temperature, and Season. Herpetological Monographs 20:64-82.
Santos, T. G.; Kopp, K.; Seies, M. R.; Trevisan, R. \& Cechin, S. Z. 2008. Temporal and spatial distribution of anurans in the Pampa Region (Santa Maria, RS). Iheringia, Série Zoologia 98:244-253.

Semlitsch, R. D. \& Gibbons, J. W. 1988. Fish predation in size structured populations of treefrog tadpoles. Oecologia 75:321-326.

Simões, P. I.; Lima, A. P. \& Farias, I. P. 2010. The description of a cryptic species related to the pan-Amazonian frog Allobates femoralis (Boulenger 1883) (Anura: Aromobatidae). Zootaxa 2406:1-28.

Simões, P. I.; Lima, A. P. \& Magnusson, W. E. 2008. Acoustic and Morphological Differentiation in the Frog Allobates femoralis: Relationships with the Upper Madeira River and Other Potential Geological Barriers. Biotropica 40(5):607-614.

Simões, P. I.; Sturaro, M. J.; Peloso, P. L. V. \& Lima, A. P. 2013. A new diminutive species of Allobates Zimmermann and Zimmermann, 1988 (Anura, Aromobatidae) from the northwestern Rio Madeira-Rio Tapajós interfluve, Amazonas, Brazil. Zootaxa 3609(3):251-273.

Sobral, I. S.; Santana, R. K de O.; Gomes, L. J.; Costa, M.; Ribeiro, G. T. \& SANTos, J. R. Dos. 2007. Avaliação dos Impactos Ambientais no Parque Nacional Serra de Itabaiana-SE. Caminhos de Geografia Revista Online 8(24):102-110.

Summers, K. 2000. Mating and aggressive behaviour in dendrobatid frogs from Corcovado national park, Costa Rica: a comparative study. Behaviour 137:7-24.

Sullivan, B. K. \& Wagner JR., W. E. 1988. Variation in advertisement and release calls, and social influences on calling behavior in the Gulf Coast toad (Bufo valliceps). Copeia 1988:1014-1020.

Taylor, B.; Skelly, D.; Demarchis, L. K.; Slade, M. D.; Galusha, D. \& Rabinowitz, P. M. 2005. Proximity to Pollution Sources and Risk of Amphibian Limb alformation. Environmental Health Perspectives 113(11):1497-1501.

Tinoco, M. S.; Ribeiro, H. C. B.; Cerqueira, R.; Dias, M. A. \& Nascimento, I. A. 2008. Habitat change and amphibian conservation in the Atlantic Forest of Bahia, Brazil. Froglog 89:1-3.

Vasconcelos, T. S.; Santos, T. G.; Haddad, C. F. B. \& Rossa-Feres, D. C. 2010. Climatic variables and altitude as predictors of anuran species richness and number of reproductive modes in Brazil. Journal of Tropical Ecology 26:423-432.

Verdade, V. K. \& Rodrigues, M. T. 2007. Taxonomic Review of Allobates (Anura, Aromobatidae) from the Atlantic Forest, Brazil. Journal of Herpetology 41(4):566-580.

Vicente, A.; Ribeiro, A. S.; Vilar, J. C. \& Oliveira, F. F. 2005. Levantamento Botânico. In: Carvalho, C. M. \& Vilar, J. C. eds. Parque Nacional Serra de Itabaiana - Levantamento da Biota. Aracaju, Ibama, Biologia Geral e Experimental - Universidade Federal de Sergipe, p. 15-37.

Vieira, W. L. S.; Santana, G. G. \& Arzabe, C. 2009. Diversity of reproductive modes in anurans communities in the Caatinga (dryland) of northeastern Brazil. Biodiversity and Conservation 18:55-66.

VolKmer, G.; DA Fonte, L. F. M.; Brum, F. T. \& Verrastro, L. 2017. Quando e onde vocaliza Sphaenorhynchus surdus (Anura: Hylidae) no sul do Brasil? Iheringia, Série Zoologia 107:e2017029.

Wells, K. D. 1977. The social behavior of anuran amphibians. Animal Behavior 25:666-693.

Whitte, G. C. \& Garrot, R. A. 1990. Analysis of Wildlife Radio-Tracking Data. San Diego, Academic Press. 383p.

Wisniewski, P. J.; Paull, L. M. \& Slater, F. M. 1980. The effects of temperature on the breeding migrations and spawning of the Common Toad (Bufo bufo). British Journal of Herpetology 6:119-121.

Zank, C.; Di-Bernardo, M.; Maneyro, R.; Colombo, P.; Fusinatto, L. A. \& DA FonTe, L. F. M. 2010. Spatial and temporal distribution of Pseudis minuta (Anura, Hylidae, Hylinae) and environmental variables related to its reproductive activity in Reserva Biológica do Lami, southern Brazil. Iheringia, Série Zoologia 100(2):145-150. 